\title{
THE INTERACTION OF POINT DEFECTS WITH LINE DISLOCATIONS IN HVEM IRRADIATED Fe-Ni-Cr ALLOYS*
}

\author{
S. L. King, M. L. Jenkins, M. A. Kirk** and C. A. English*** \\ Department of Materials \\ University of Oxford, Parks Road, Oxford, OX1 3PH. U.K. R \\ **Materials Science Division, Argonne National Laboratory \\ Argonne, IL 60439
}

***MDD, B.393, Harwell Laboratory

Didcot, Oxon, OX11 ORA, U.K.

CONF-900623--18

DE90 017691

\section{May 1990}

\begin{tabular}{|c|}
\hline 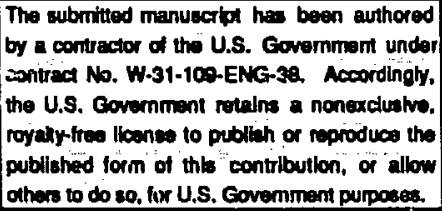 \\
\hline
\end{tabular}

\section{DISCLAIMER}

\begin{abstract}
This report was prepared as an account of work sponsored by an agency of the United States Government. Neither the United States Government nor any agency thereof, nor any of their employees, makes any warranty, express or implied, or assumes any legal liability or responsibility for the accuracy, completeness, or usefulness of any information, apparatus, product, or process disclosed, or represents that its use would not infringe privately owned rights. Reference herein to any specific commercial product, process, or service by trade name, trademark, manufacturer, or otherwise does not necessarily constitute or imply its endorsement, recommendation, or favoring by the United States Government or any agency thereof. The views and opinions of authors expressed herein do not necessarily state or reflect those of the United States Government or any agency thereof.
\end{abstract}

Submitted to the 15th Symposium on "Effects of Radiation on Materials", June 17-21, 1990, Nasiville, Tennessee.

*Work supported in part by Oxford, AERE Harwell, and the U. S. DOE, BES-Materials Sciences, under Contract W-31-109-Eng-38. 
ASTM 15th Symposium on Effects of Radiation on Materials. June 17-21, 1990

Nashville, Tennessce, U.S.A..

S L King', M L Jenkins', M A Kirk², and C A English ${ }^{3}$.

The Interaction of Point Defects with Line Dislocations in HVEM Irradiated Fe-Ni-Cr Alloys.

${ }^{1} D$. Phil. student and Senior research fellow respectively; Department of Materials, University of Oxford, Parks Road, Oxforu, OX1 3PH, U.K.,

${ }^{2}$ Metallurgist; M.S.D., Argonne National Laboratory, 9700 S. Cass Avenue, Argonne, Illinois 60439, U.S.A.,

${ }^{3}$ Principal Scientific Officer; MDD, B.393, Harwell Laboratory, Didcot, Oxon, OX11 0RA, U.K.. 


\section{Abstract}

This paper presents results of a study of the interaction of point defects produced by high voltage clectron microscope (IIVEM) irracliation with pre-existing dislocations in anstenitic Fo-15\% \& $25 \% \mathrm{Ni}-1 \% \% \mathrm{Cr}$ alloys, aimed at the determination of the mechanisms of climb of dissociated dislocations. Dislocations were initially characterized at sub-threshold voltages (here $200 \mathrm{kV}$ ) using the weak-beam technique. These dislocations were then irradiated with $1 \mathrm{McV}$ clectrons in the Argonne IIVEM before being returned to a lower voltage microscope for post-irradiation claracterization. Interstitial climb was seen only at particularly favourable sites, sucl as pre-existing jogs, whilst vacancies clustered near dislocations, forming stacking fault tetralicdra. (SF'T). Partial separations were also observed to have decreased after irradiation. The post-irradiation configuration was found to depe. $\perp$ strongly on both dislocation character and pre-irradiation dislocation configuration. These results, and their relevance to the void swelling problem, are discussed.

Kevwords: Dislocation climb, IIVEM irradiation, TEM, wcak-bcam imaging, Fe-Ni-Cr alloys, austenitic steels, SFT, jog-climb. 


\section{Introduction}

Anstenitic stainless stcels have become widely cmployed within the nuclcar industry, their principal uses being for fucl elcment cladeling, supports and spacers, and control-rod guide tubes within the core of fast rearturs. Concommitent with these applications, however, lave come a varicty of induced or enhanced radiation damage effects. Almost all these effects are detrimental, especially void swelling, irradiation crecp and embrittlement, which seriously limit the useful life of reactor components necessitating costly and difficult renewal. In the hostile environment of a commercial fast reactor, for example, in which core structures are subject to dose rates of $40-100$ displacements per atom (dpa)/year at temperatures in the range $500-600^{\circ} \mathrm{C}$, the void swelling problem, first observed in 316 stainless stecl by Cawtlorne and Fulton in 1967 [1], is potentially partic larly severe (up to $10 \%$ per year). This can lead to buckling and weakening of core components, making their removal difficult and expensive. Transmission electron microscopy (TEM) obscrvations of thesc swollen stecls, under a variety of irradiation conditions have been large in number (c.g. [2-5]) and show that a complicated microstructure of voids and dislocation networks has evolved.

In the phenomenon of void swelling, it was rccognised as early as 1959 that a tendency for clislocations to show a preference for interstitials over vacancies may play a crucial róle [6]. This tendency is expected because interstitials have a larger strain field than vacancies, and so have a bigger elastic interaction with line dislocations. This preference was formalized in terms of a dislocation "bias" for interstitials [ $[\bar{l}$ ] in 1975 . In the presence of biased sinks for interstitials, neutral sinks such as voids reccive a net flux of vacancies and so grow. Void embryos are thought to be stabilized by gas atoms such as IIc or II formed by $(n, \alpha)$ or $(n, p)$ transmutations respectively. It is clear therefore that the mechanisms of interaction of nigrating point defects with pre-existing dislocations, which might involve glide, climb and/or diffusion processes, is central to the determination of accurate dislocation sink strengths, leading eventually to a better understanding of radiation damage phenomena. In view of the importance of pre-existing dislocations and the known complexity of dissociated dislocation climb in low SFE materials (sce below), we have carried out and report here a systematic study of the interaction of irradiation induced point defects with line dislocations in some model anstenitic Fe-Ni-Cr alloys with base composition similar to those of technological stcels. 
Prior to the general application of TEM imaging to the determination of the climb mechanisms of dissociated dislocations a number of theoretical models were propnsed 18. 12], involving cillur constriction or primary nucleation onto individual partials or the stacking fault. itself. Grillie et al (1977 [13]), in calculating energies of the intermediate configurations, found certain circumstances in which the Thomson \& Ballufri mechanism [10] could be energetically favourable. This mechanisun results in the formation of an extended double jog pair via the nucleation of a prismatic loop of the same Burgers vector as the parent dislocation on one of the partials. There have since been numerous observations of voids [c.g. 14-17] and high densities of both interstitial and racancy loops [e.g. 18-23] close to irradiated dislocations, suggesting that dislocations can act as sinks for hoth interstitials and vacaucies. Precise determination of both the nature of all the damage and its relation to the line was, however, often beyond the resolution of the tecinniques employed.

Weak-beam imaging [24,25], first employed to study irradiated dissociated dislocations by Carter in a low stacking fault energy (SFE) copper-aluminium (CuAl) alloy [26,27], confirmed the fine scale of this line damage and found loops to have nucleated onto the partials themselves. However, it was left for the painstaking study by Cherns et al [28] of HVEM-irradiated dissociated dislocations in $\mathrm{Cu}-13 \% \mathrm{Al}$ to deduce that climb was proceeding via the nucleation of interstitial perfect prismatic disiocation loops (or Frank loops which subscijuently unfault) directly onto the partials, the partial of greater edge character generally being favoured. As distinct from the Thomson \& Balluffi mechanisn, nucleated loops were not necessarily of the same Burgers vector as the parent dislocation. These "loop-jogs" were then acted upon by the osmotic climb force [29] arising from th.. local interstitial super-saturation, twisting them towards edge orientation and leading to complex configurations whose structure depended on the orientation of parent partial and loop. At elevated temperatures the same basic mechanism operated although irradiated dislocations assumed different final configurations which were attributed to interactions between the "loop-jogs" and the second partial. The final configurations frequently contained a number of Shockley dislocation dipoles. Similar, nucleation based, mechanisms leading to dipole formation have been proposed in silicon [30], gallium-arsenide (GaAs) [31], copper-germanium (CuGe) [23,32] and, uncis vacancy super-saturation, in CuAl [33] (see also the 1984 review by Cherns [34]). 
The smaller pre-irradiation partial separation of screw dislocations was believed responsible for further increasing the innuence of the sccond partial, such that at elevated temperatures cridence only for the nucleation of loops with the same Burgers vector as the total dislocation was seen. Cherns et al hypothesized that increasing the SFE of the system studied may also affect the Burgers vectors of nucleated loops, possibly favonring the operation of the Thomson \& Balluffi mechanism [10]. Ilardy and jenkins attempted to test this hypothesis by analysing any dependence of climb mechanism on partial separation by studying the higher SFE Cu-10\%Al, and to investigate any segregation effects arising from the binary CuAl system by studying pure silver, which has a similar SFE [35] to Cu-13\%Al [36]: Cu-10\%Al showed behaviour entirely consistent with that of Cu-13\% $\mathrm{N}$ and the same mechanisms as those isolated by Cherns et al [28] werc thought to be operating [32]; silver, however, exhibited markedly different behaviour in which dissociated dislocations appeared to constrict at a very early stage and dense wedge-like regions of SFT were seen to form close to the dislocation. Interstitial loops associated with the dislocation were not seen [3i]. The authors proposed that, after constriction, dislocations act as good sinks for interstitials, leaving a net. varancy super-saluration such that varancy clusters are able to aggregate and form SFT.

\section{The present study}

Results are presented here for two pure teruary alloys with 15 and 25 at.\% nickel respectively, both containing $1 \bar{r}$ at. $\%$ chromium (balance iron), which form part of a larger study aimed at investigating the effects of partial separation (with an $\mathrm{Fe}-40 \% \mathrm{Ni}-17 \% \mathrm{Cr}$ alloy; via the SFE dependence on nickel content $[38,39]$ ) and minor element segregation (with the addition of small amounts of silicon and moiybdenum to an $\mathrm{Fe}-15 \% \mathrm{Ni}-17 \% \mathrm{Cr}$ alloy) on point defect-dislocation interactions. Essentially similar observations were made in both alloys and distinctions between them are not dwelt upon at this stage; the aim of this paper is rather to highlight, qualitatively, some of the general trends which are representative of the larger project. Thompson's notation [40] is used throughout.

\section{Experimental}

Single crystals, grown by the Bridgman metlıod, were first orientated by Laue backdiffraction prior to bcing scctioned parallel to a (111) slip plane by spark machining. $3 \mathrm{~mm}$ discs were then spark cut from these sections and a low density of glissile dislocations lying in the foil was introduced by slight bending. Electron transparent foils were prepared by double-jet electro- 
a)

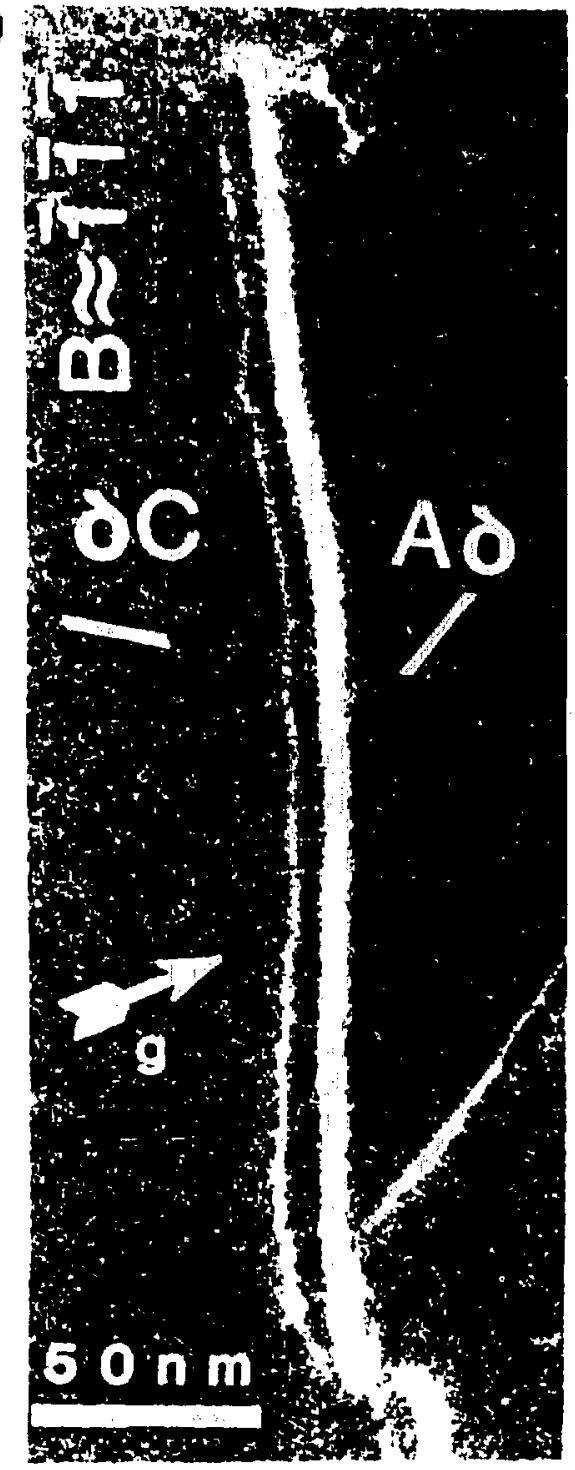

b)

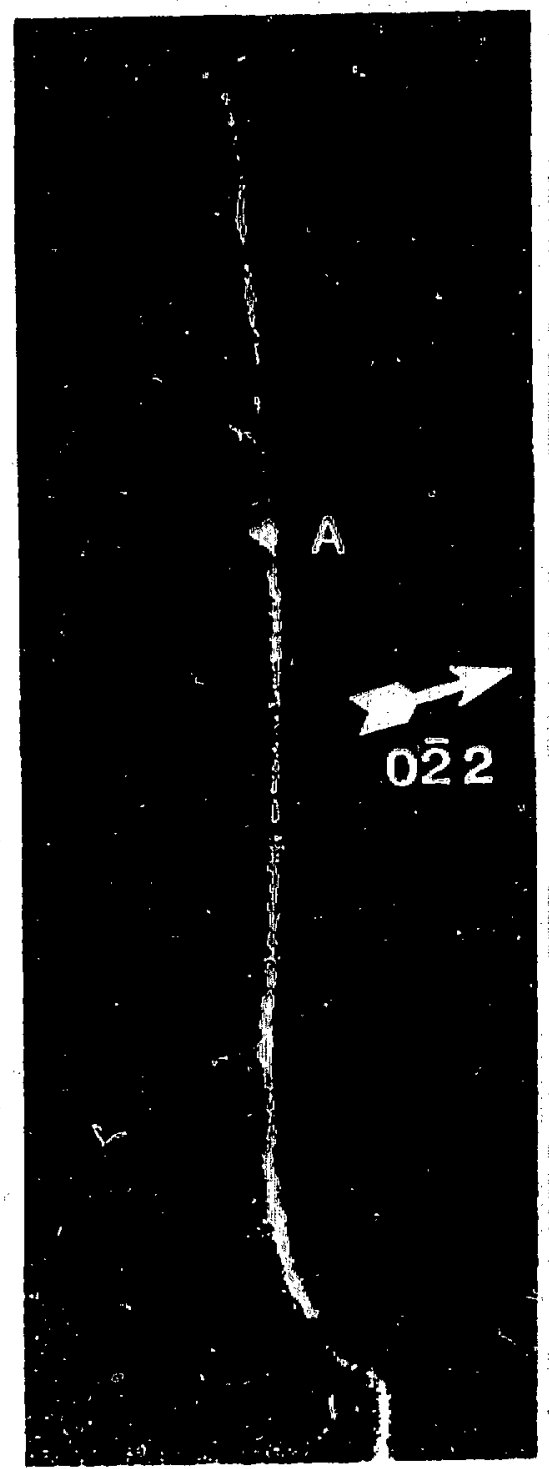

c)

10
17
12
2
0

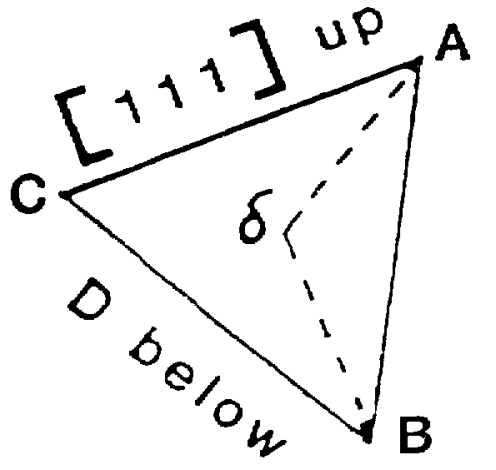

Fig.l. $75^{\circ}$ Dislocation in Fe-15\% Ni-17\% Cr (at. $\%$ )

$0.05 \mathrm{dpa}$ at $\sim 400^{\circ} \mathrm{C}$ 


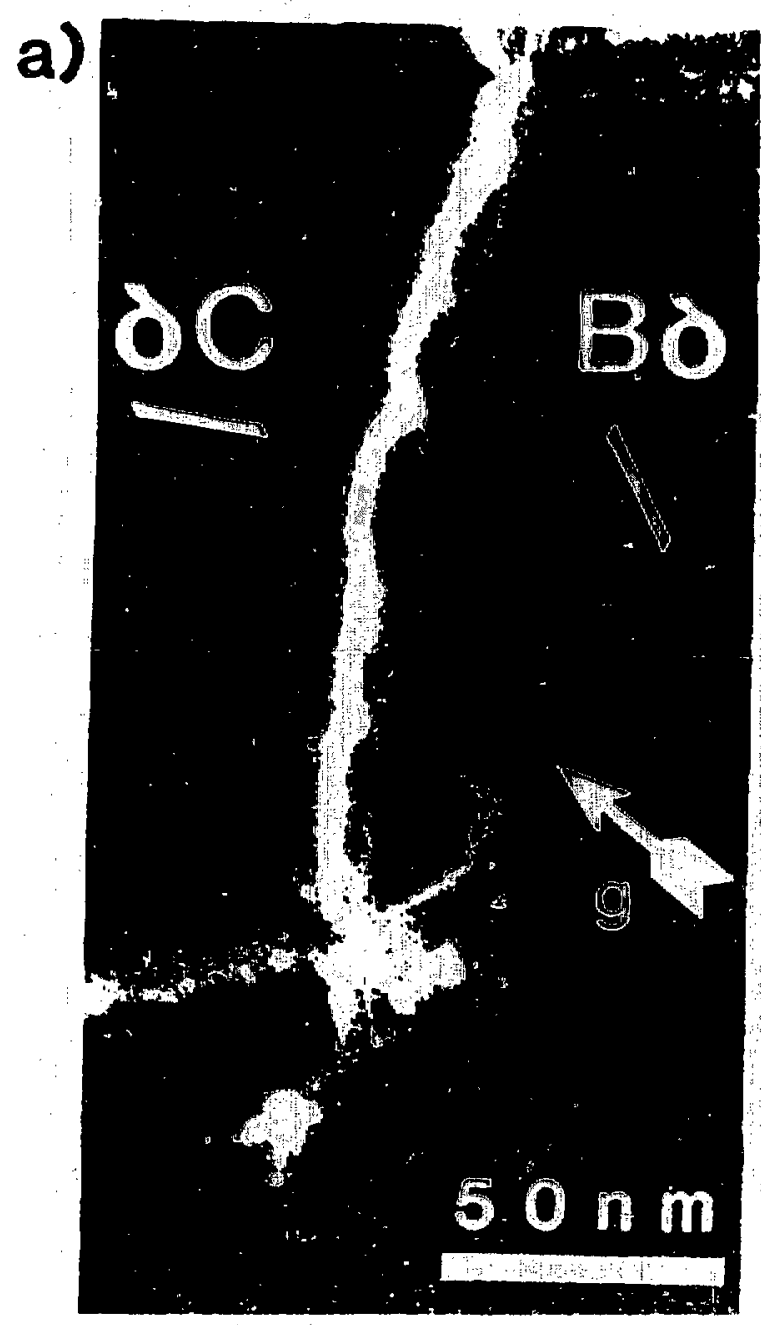

b)

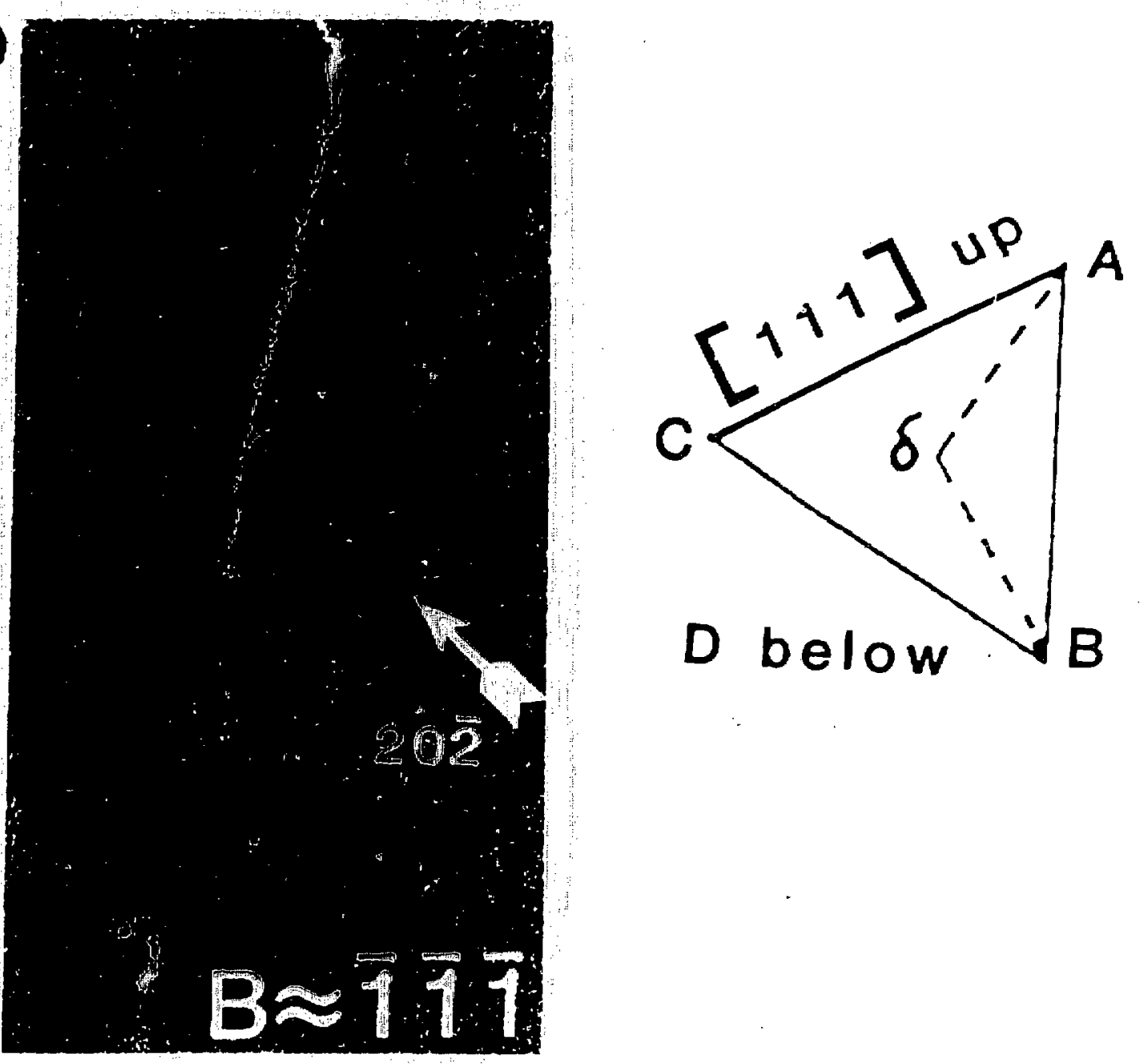

$50-70^{\circ}$ Dislocation $\frac{\mathrm{Fig} \cdot 2 .}{\mathrm{in} \mathrm{Fe}-15 \% \mathrm{Ni}-17 \% \mathrm{Cr} \text { (at.\%) }}$

$0.05 \mathrm{dpa}$ at $\sim 400^{\circ} \mathrm{C}$ 
polishing at $28-30 \mathrm{~V}$ in a solution of $4 \%$ perchloric acid in anhydrous methanol at $-55^{\circ} \mathrm{C}$. Perforation was detected by eye with the specinens being washed finally in dried ethanol. Ideally long curved dislocations were chosen, to provide a range of oricntations, which were characterized by weakbeam imaging at $200 \mathrm{kV}$ (a voltage at which sub-threshold damage was acceptable) in either a Philips CM30 or EMI430 electron microscope using the Howie-Whelan $\tilde{\mathrm{g}} \cdot \overline{\mathrm{b}}=0$ invisibility criterion [41]. These dislocations were then irradiated with $1 \mathrm{MeV}$ electrons in the Argonn: il VEa.i. The elect:on density was measured using a Faraday cup placed at the IIVEM bean centre from which the level of displacement damage was calculated using a value for the displacement cross-section of 70 barns [42]. Irradiations were performed at temperatures in the range $390-430^{\circ} \mathrm{C}$; at lower temperatures the formation of very fine scale bulk damage was observed, which eventually obliterated the dislocation inage entirely, whilst at higher temperatures what may have been the vely early stages of sigma phase transformation at the surfaces of the thin filn impaired weak-beam resolution beyond acceptable limits (the first signs of the transformation itsclf did not become criclent in the HVEM by strong-beam imaging below about $600^{\circ} \mathrm{C}$ ). The liot stage had been calibrated using an externai thermocouple in a dummy column but experimental problems encountered in this procedure inclicate that the uncertainty in temperature measurenents is about $\pm 50^{\circ} \mathrm{C}$. Beam heating should be only a few degrees. Finally the specinens were transferred back to a Philips EM430 electron microscope for post-irradiation cliaracterization of the observed damage making use of both the $\overline{\mathrm{g}} \cdot \overline{\mathrm{b}}=0$ invisibility criterion and the inside/outside contrast method [e.g. 43] for loop analysis. Sufficient reflections were used to ensure that any perfect or Frank dislocation variant lıad $\overline{\mathrm{g}} \cdot \overline{\mathrm{b}}=0$ in at least one reflection. Where possible true weak-beam conditions were used [see 24,25$]$ but occasionally the deviation parameter was reduced below $2 \times 10^{-2} \AA^{-1}$ because a sur[ace contaminant layer, resulting from the IIVEM irradiation, reduced the already weak inage intensities. This problem was particularly prevalent in irradiations of the $15 \%$ nickel alloy.

\section{Results}

In figure 1 we sce a $75^{\circ}$ dislocation section in $\mathrm{Fe}-15 \% \mathrm{Ni}-17 \% \mathrm{Cr}$, irradiated to $\sim 0.05$ dpa at $400^{\circ} \mathrm{C}$. Figures $1(\mathrm{a})$ and (b) show $\overline{\mathrm{g}} \cdot \overline{\mathrm{b}}_{\mathrm{T}}=2$ (where $\tilde{\mathrm{b}}_{\mathrm{T}}$ is the total Burgers vector of the dislocation) for the dislocation before and after irradiation respectively whilst (c) shows the near screw partial out of contrasi. In common with all other figures in this paper these micrographs are selected from a larger contrast set taken in all principal reflections; of the [111], [112], [121] and [211] poles. $\overline{\mathrm{B}}$ 
refers to the beam direction and the white arrows mark the operating diffraction vector (i்).

Burgers vectors $(\tilde{b})$ of the individual partials are indicated by short white bars. Features which sliould be noted are:

(a) befure irradiation the line exhibits an even, constriction free, dissociation.

(b) after irradiation the partial separation has narrowed; however the dislocation is still dissociated.

No new constrictions liave formed aral there is no evidence for major climb motion of the line. $A$ defect cluster $(A)$ is visible very close to the line; this cluster is found to be visible in every reflection and hence lias contrast which does not fit any perfect or Frank loop variant. Suclı contrist. would be consistent with a three dimensional (3D) defect such as an SFT.

In (c) the formation of a line of very fine scale cluster clamage along tlie dislocation is evident.

These clusters also cxhibited contrast inconsistent with any simple loop variety suggesting that they are 30. It should be noted that this line of chuster damage lies very close to the dislocation and is assumed to have uncleated within the strain field of the dislocation core. Images may therefore be supcrimposed for most foil orientations; in this reflection the foil is tilted about $20^{\circ}$ in a sense favourable for resolving separately the dislocation line and the clusters beneath.

Figure 2(a) slows an initially : videly dissociated but heavily jogged $50-70^{\circ}$ dislocation, a. evidenced by the large number of constrictions along the line [44]. After irradiation to $\sim 0.05$ pa (fig.2(b)) the partial separation has narrowed and the dislocation exhibits an even dissociation along most of its length, the constrictions having disappeared. Other reflections (not shown) in this scries slow the nucleation of cluster damage along the line similar to that of figure $1(\mathrm{c})$. In common with the dislocation of figure 1 there is no evidence for the formation of new jogs or far major climb motion of t.lic now evenly dissociated line.

A screw dislocation containing a number of pre-existing jogs, some of which are indicated $(J)$, is siown in figure 3(a) prior to irradiation. After irradiation (figs.3(b,c)) the dislocation has assumed a zig-zag configuration with points of the zig-zag apparently corresponding to the positions of the pre-existing jogs. This dislocation is not thought to have climbed into a helix but rather to be two dimensional (2D) as explained in the discussion below. $\tilde{\mathrm{g}} \cdot \tilde{\mathrm{b}}_{\mathrm{T}}=2$ for the total dislocation in this micrograplı and evidence that the short, straight sections of the line are still dissociated is confirmed by contrast seen from the stacking fault in figure $3(\mathrm{c})$ for which $\overline{\mathrm{g}} \cdot \tilde{b}_{\mathrm{T}}=0$. The dislocation may be constricted at the jogs. A number of interstitial Frank loops are seen to liave nucleated in the bulk and two of each type are labelled $(A=\overrightarrow{\alpha A} ; B=\overrightarrow{\beta B} ; C=\overrightarrow{\gamma C} ; D=\vec{D} \delta)$. One of the loops " $\Lambda$ " 


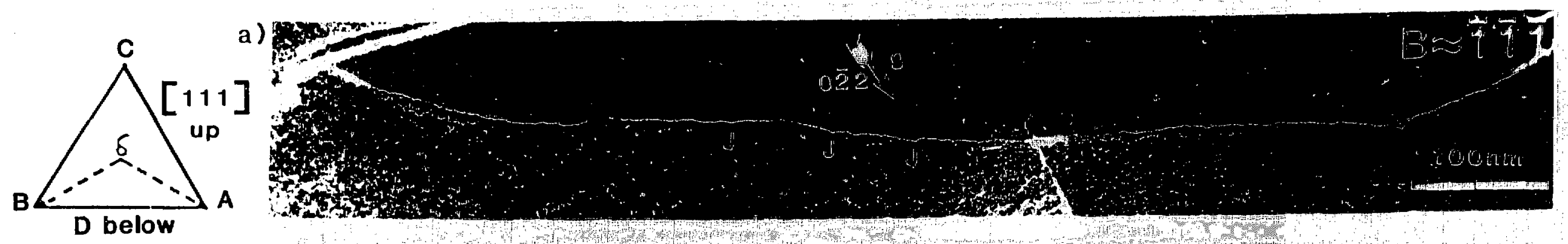

\section{b)}
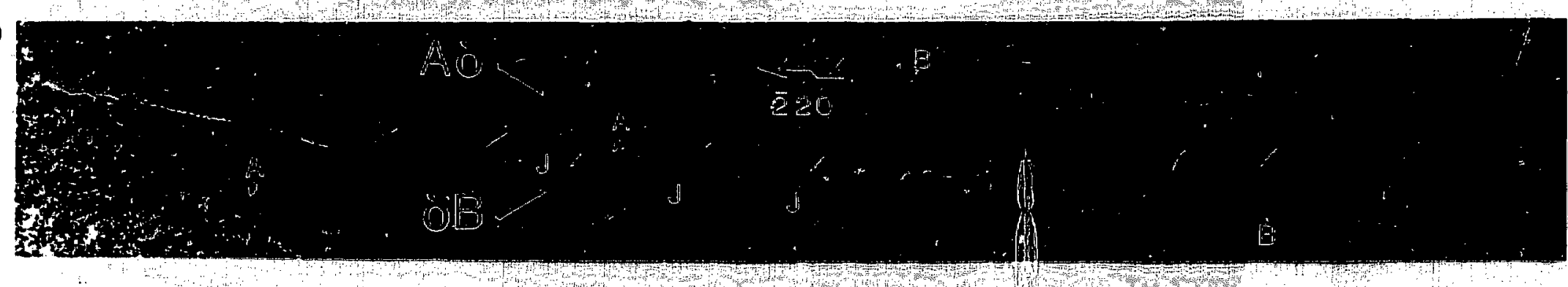

c)
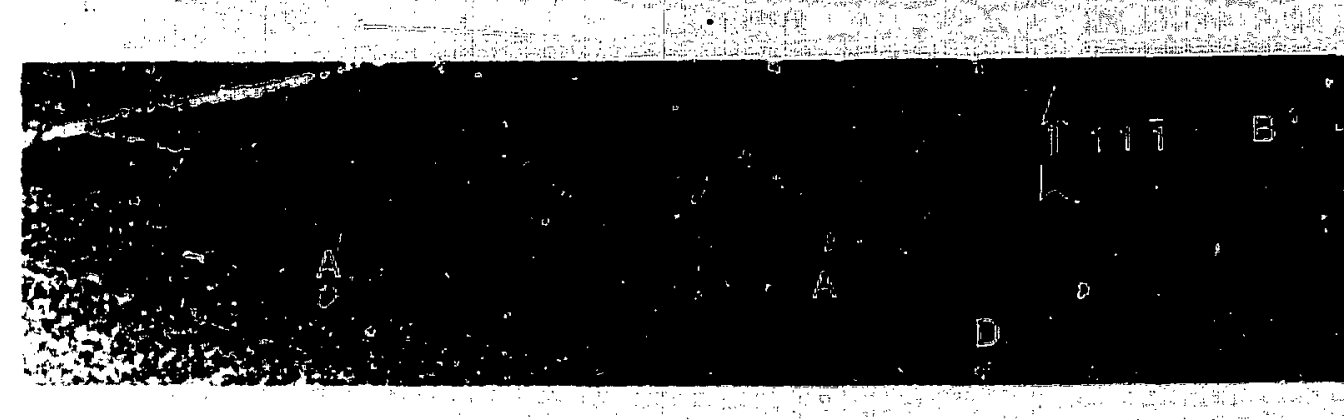

Hent

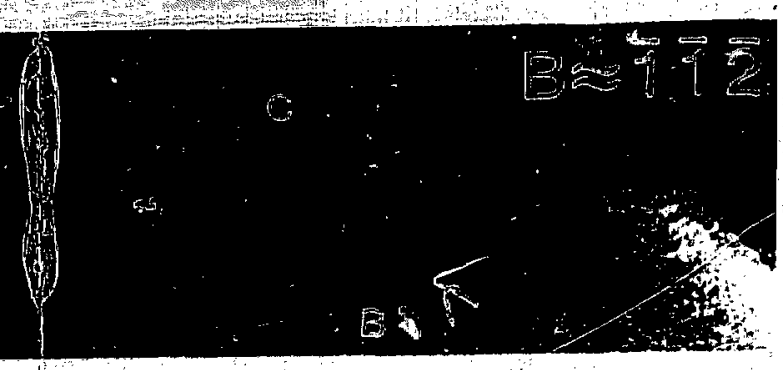

Fig. 3. Screw Dislocation in Fe-15\% N-17\% Cr (at.\%) 0.05 dpa at $\sim 400^{\circ} \mathrm{C}$ 


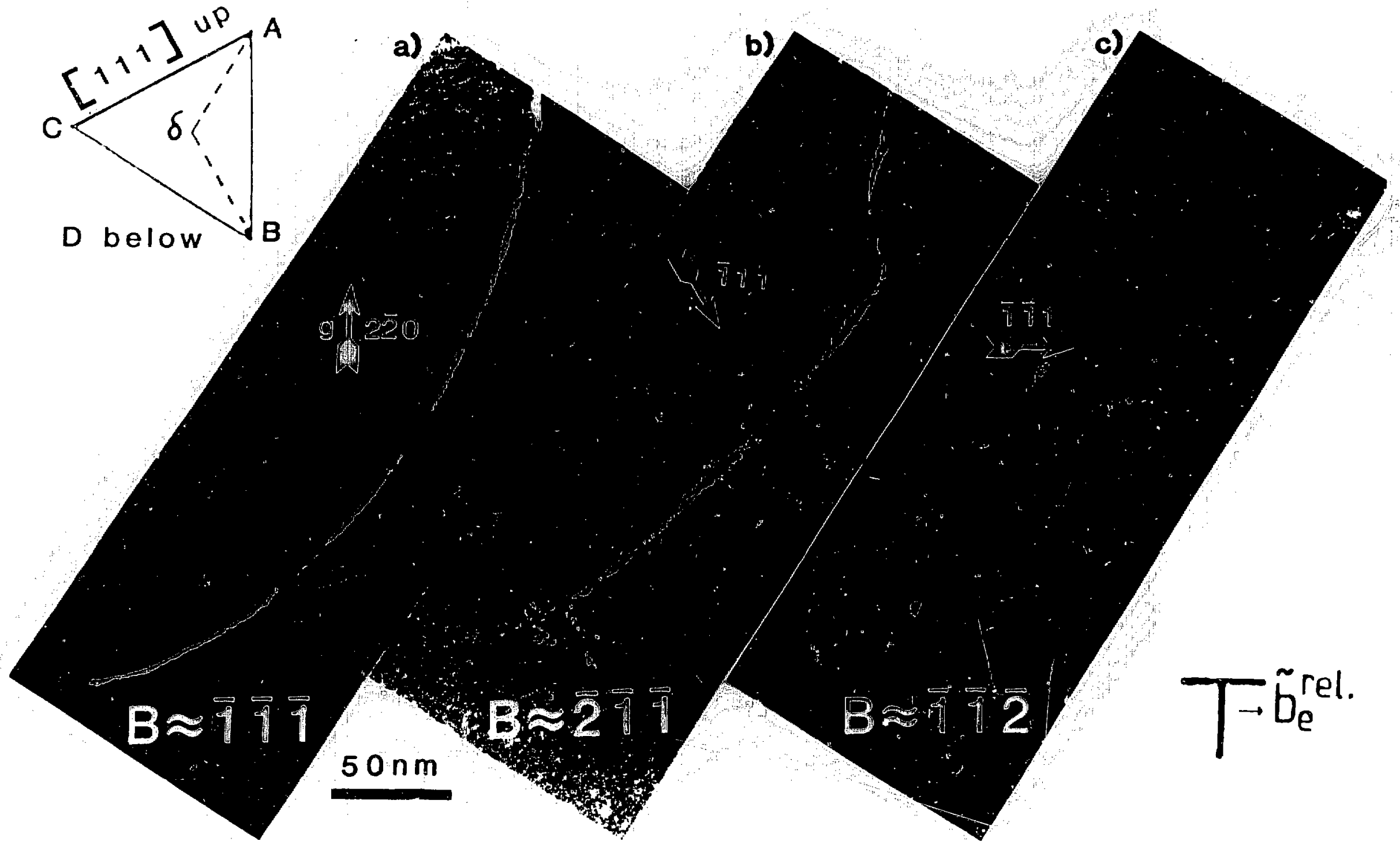

Fig.4. Near screw to $60^{\circ}$ Dislocation in Fe $-25 \% \mathrm{Ni}-17 \% \mathrm{Cr}$ (at.\%) $0.1 \mathrm{dpa}$ at $\sim 430^{\circ} \mathrm{C}$ 
appears to lie on, or very close to the dislocation in figare 3(b) but is shown some distance away in figure 3(c). This loop has not reacied with the dislocation and in fact lies some distance below it. In all refleciions taken of this dislocation after irradiation no evidence was seen for any loop nucleation along the line.

The motion and straightening of an initially curved dislocation after $\sim 0.1$ dpa irradiation is seen in figure 4 , leaving a discrete line of cluster damage close to its original position. Figure $4(a)$ shows the dislocation prior to irradiation, with both partials in contrast, whilst figures $4(\mathrm{~b})$ and $4(c)$ shew the left hanc partial $\overrightarrow{\delta B}$ and the stacking fault after irradiation respectively. Whilst the stacking fault contrast in $4(c)$ is weak the dislocation is apparently rot entirely constricted. Individua! fcatures within the line of cluster damage cuuld not be cliaracterized eitlıer by the $\tilde{\mathrm{g}} \cdot \tilde{\mathrm{b}}$ invisibility criterion or by looking for characteristic insicle/outside contrast and are probably 3D. Many of these clusters seem to show arrow-head contrast typical of vacancy SFT in some reflections taken after irradiation, however, micrographs have been selected here to show the relative positions of clusters and line.

A clearer observation of the nature of cluster damage along dislocations is provided by figure 5 , in which an Fe-25\% Ni-17\% Cr alloy has been irradiated to a slightly higher dose and the

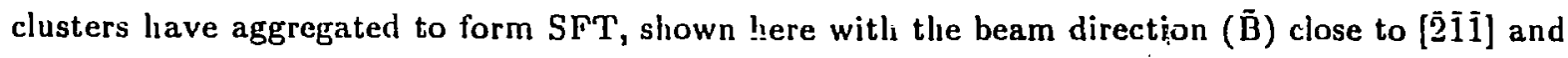
the diffraction vector $\tilde{\mathrm{g}}=[? \overline{1} \overline{1}]$. Almost all the observed bright spots of contrast were resolvable as SFT in at least one of the reflections taken of this dislocation after irradiation.

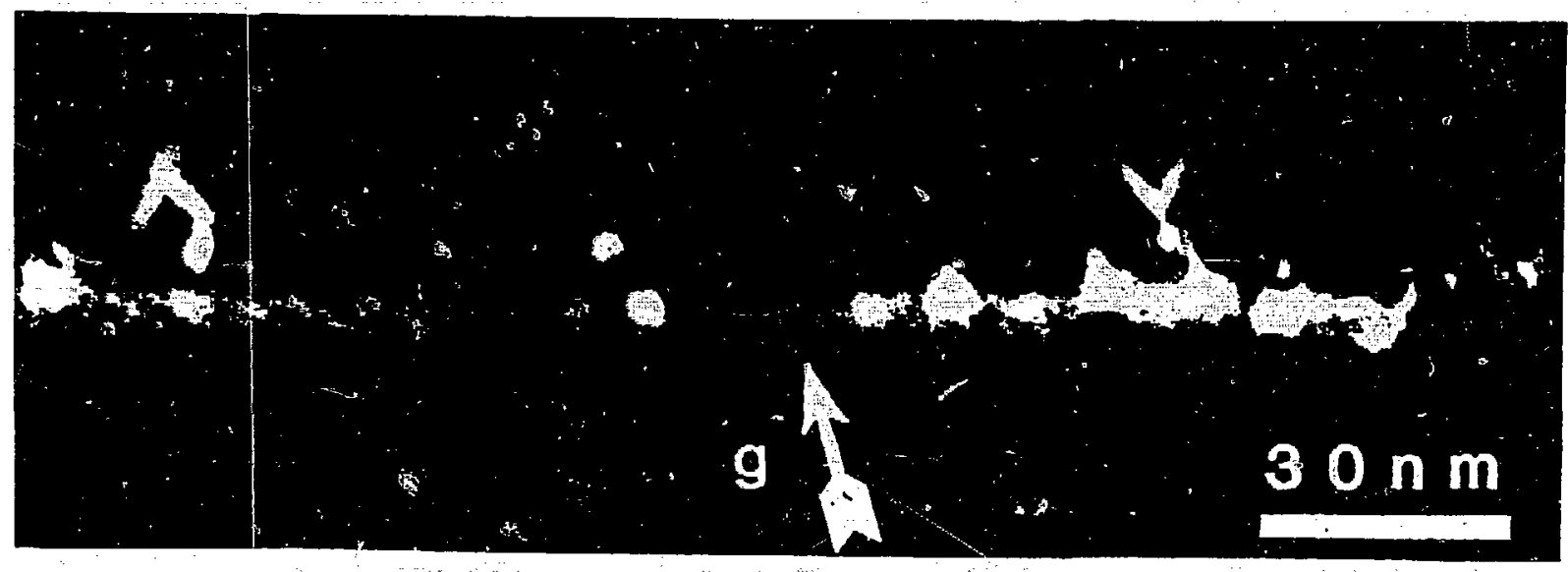



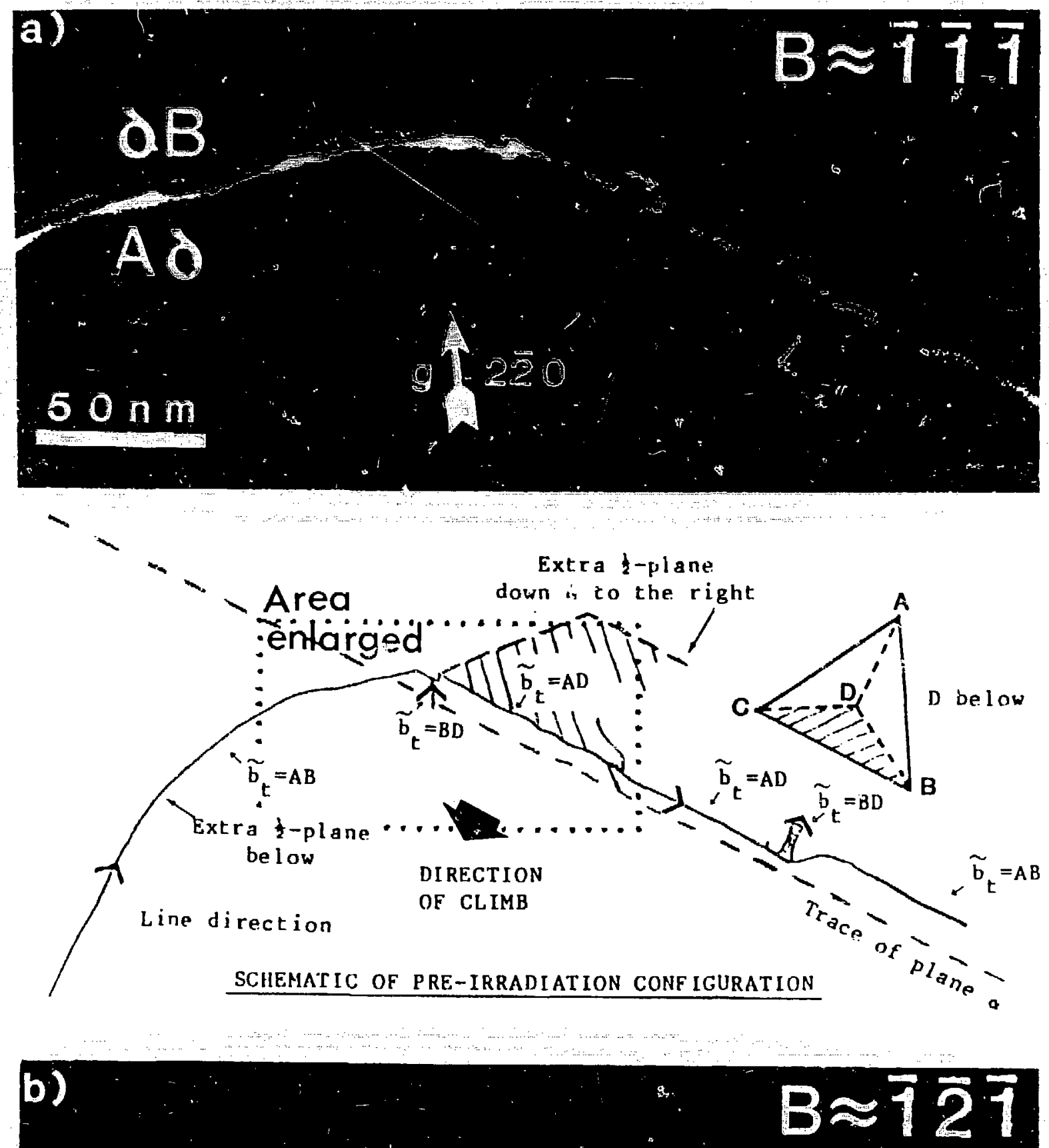

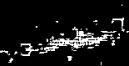
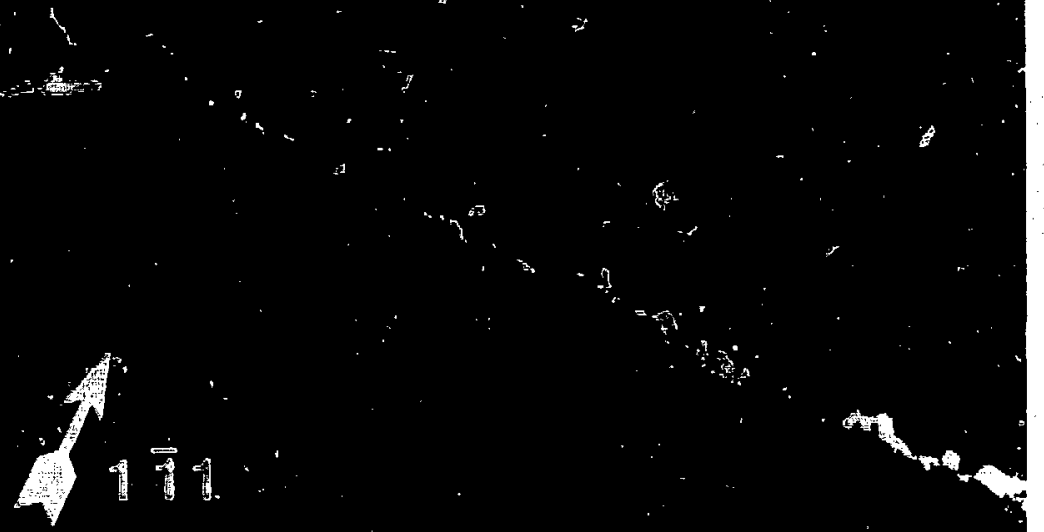

Fig.6. Glissile and Sessile Dislocations in $\mathrm{Fe}-25 \% \mathrm{Ni}-17 \% \mathrm{Cr}$ (at.\%) $0.11 \mathrm{dpa}$ at $\sim 430^{\circ} \mathrm{C}$ 
In figure $6(a)$ a more complex configuration is shown prior to irradiation: $\Lambda$ glissile disl-

ocation. with $\overrightarrow{\mathrm{b}}_{\mathrm{T}}=\overrightarrow{\mathrm{AB}}$ on $\delta$ on the left hand side of the figure, has intersected with one of a number of dislocations $\vec{b}_{T}=\overrightarrow{\mathrm{BD}}(\alpha)$, which are stecply inclined and difficult to sec in this reflection, to form the perfect sessile dislocation $\overrightarrow{\mathrm{b}}_{T}=\overrightarrow{\mathrm{AD}}(\alpha / \delta)$. The slip trace aloug which dislocations $\overrightarrow{\mathrm{BD}}$ have glided lies accurately along the lire of intersection of planes $\alpha$ and $\delta$ and is visible running from lower right to top left in the figure. The reaction product $\overrightarrow{\Lambda D}$ is sessile in toth $\alpha$ and $\delta$ and should therefore lie exactly on this trace. Dislocation $\overrightarrow{A D}$ is initially fairly straiglit and disiecation $\overrightarrow{A B}$ cxhibits a relatively even dissociation along its entirc length. Note also that the dislocation is jogged to the right at the point of intersection. The initial configuration is shown schematically by the line diagram at centre.

In figure $6($ b) the dislocation is shown after irradiation, with the upward foil normal (opposite to the beam dircetion B) close to [121]. At this tilt planes $\alpha$ are nearly vertical. Notice here the disappearance of the jog at the point of intersection of $\overrightarrow{A B}$ and $\overrightarrow{B D}$ (confirmed by other reflectio.ıs) and that dislocation $\overrightarrow{A D}$ is now sharply cusped to the left of the original trace along which it was formed. Dislocation $\overrightarrow{A B}$ has glided downwards, away from a line of clusters which continues past the point of intersection of $\overrightarrow{\mathrm{AB}}$ and $\overrightarrow{\mathrm{BD}}$. These clusters slow contiast inconsistent with any simple perfect or Frank loop in the full contrast series and some of them are occasionally resolvable as SFT; it is therefore likely that they are 3D vacancy clusters, similar to those seen in other irradiations, some of which have aggregated sufficiently to be visible as SFT.

\section{Discussion}

'Taking an overall view of the micrograplıs one slould first note that straight line dislocation sections are not apparently climbing. As distinct from $\mathrm{CuAl}$ [28] there is no copious interstitial loop nucleation onto the partials or evidence for the formation of reaction products suclı as Shockley dipoles. The belıaviour of irradiated dislocations in $\mathrm{Fe}-\mathrm{Ni}-\mathrm{Cr}$ is broadly similar to that scen in silver [37] in that partial dislocation separations are observed to have decreased after irradiation. In silver micrographs taken in-situ in the HVEM suggested that partials constrict entirely, however it is uncertain whether dislocations were still dissociated by an amount below the resolution limit of the instrument. Partials are plainly still dissociated in these $\mathrm{Fe}-\mathrm{Ni}-\mathrm{Cr}$ alloys. Another sinilarity witl silver is the formation of cluster damage close to irradiated dislocations. Contrast arising from these clusters suggests that they are $3 \mathrm{D}$ and observations tirat these clusters form within the 
conpressional strain ficld of dislocictions of sufficient edge character (see below), coupled with those of inclividual clusters occasionally being resolvable directly as SFT, suggests that, in common with silver, this damage is vacancy in nature. It is hoped that further research will lead to an explanation of the difrerences in behaviour shown by irracliated clislocations $\mathrm{in} \mathrm{CuAl}$, silver and $\mathrm{Fe}-\mathrm{Ni}-\mathrm{Cr}$ and questions arising from these differences are left for a later date. This discussion focuses rather on rationalizing our obscrvations in terms of a physical model of how point defects are interacting vi il dislocations in our materials.

The behaviour typical of straight, cvenly dissociated, dislocations is exemplitied in figure 1. No jog or loop nucleation directly onto the partials is secn, but a line of cluster damage has formed very close to the dislocation core. Sinilar lines of damage were seen in all irradiations of mixed and edge dislocations and these lines accurately mark the pre-irradiation dislocation position. This is of particular relevance to the discussion of figure 4 below.

Near edge and screw dislocations are shown in figures 2 and 3 respectively. The disappearance of constrictions in figure 2 can be explained simply in terms of jog climb. As is indicated in figures $7(a)$ and (b), climb forces on a pair of equal, and oppositc, jugs (labelled "Up" and "Down") in a mixed or edge dislocation will be such as to cause the jogs to climb together and annihilate uncler, say, a net interstitial super-saturation for the scrse of the jogs as shown. For the situation shown in ïgure 2, wl ere there are a great many jogs, the direction of motion of an inclividual jug is unimportant.

As clislocations approach screw orientation (figure 3) the climb forces on the jogs will tend away from the line direction and, presumably, a point is reaclied beyond which these forces will overcome the line teusion forces which tend to keep the dislocation straight. Jogs will now not climb together and annililate but will instead give rise to a two dimenzional (2D) zig-zag configuration as shown in figurc $7(\mathrm{c})$. We bclieve this to be the case for the screw dislocation of figure 3 , in which the climb forces on the jogs act perpendicular to the line. The numbers 1,2 and 3 in both rigures 7 ancl 8 refer to initial, intermediate and final configurations respectively. Small arrows represent the directions of climb forces on the jogs whilst $\tilde{b}$ is the Burgers vector and $\tilde{\xi}$ the positive line clirection. The post-irradiation configuration of figure 3 would scen unlikely to be helix formation, as previously thought possible [45] since no depth oscillations are observed in the weak-beam images, the intensities of which are very sensitive to depth within the foil [25]. These fringes would be separated by $<50 \AA$ under the conditions operating. Were the line to have climbed into a helix with 
a)

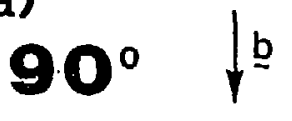

1

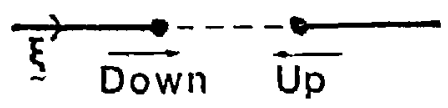

$y$

2

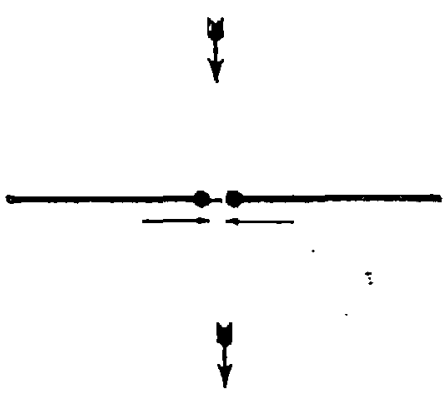

3

\section{FIGAE 7}

b)

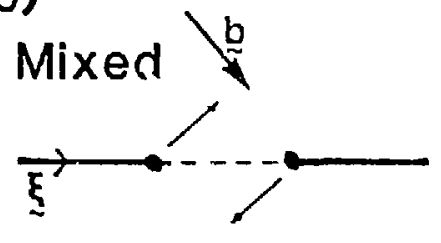

c)
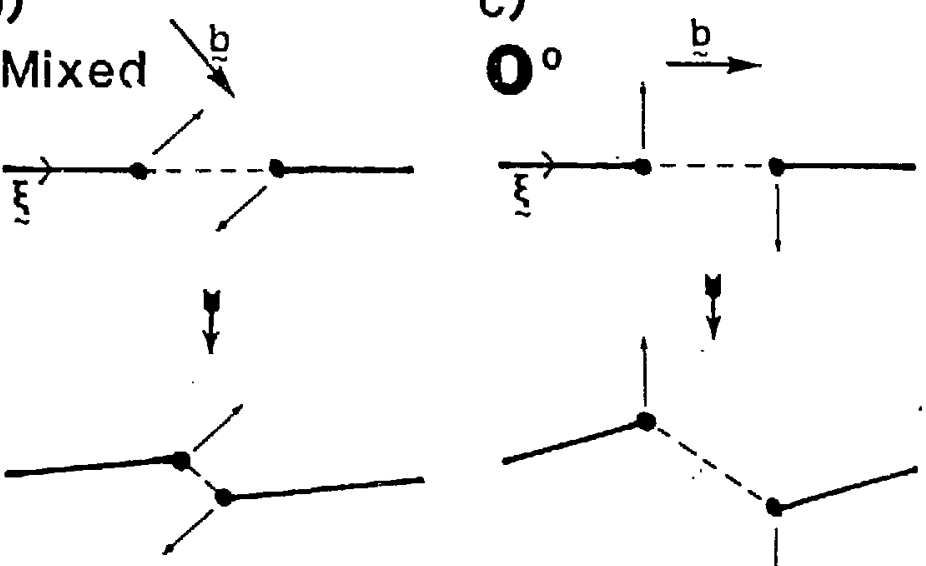

$y$
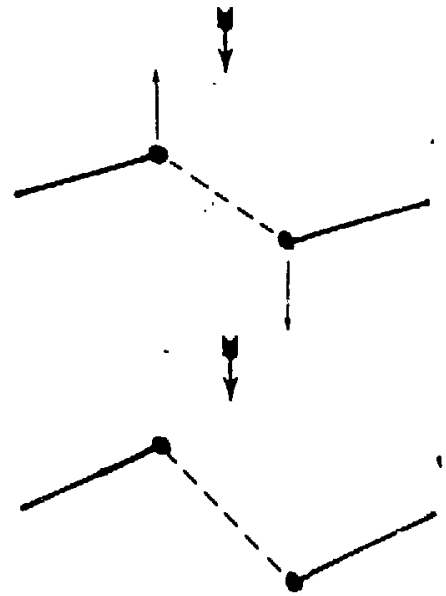

the observed pitch, which is little less than the thickness of the foil $(\sim 1000 \AA)$, it would be extremely loosely wound. One might, however, expect the radius of the helical coils to approach the period of the turns $[46,47]$, yielding clearly visible thickness oscillations. Secondly, regions of the disl-) ocation between jogs are still dissociated; although a mechanism whereby a dissociated dislocation can climb into a helix has been proposed by Cherns et al [28-their figure 15], the nucleation of a high density of interstitial loops directly onto the line must be invoked. Whilst the mechanism of Cherns et al "mops up" loop debris prior to formation of the final configuration, at no stage, in this or any other irradiation, was there evidence for any CuAl-like loop nucleation directly onto dislucations. All the irradiations performed suggest, rather, that dissociated dislocation sections do not climb, preventing helix formation. Finally, were copious numbers of jogs to have nucleated along these sections to enable them to climb, then the final zig-zag structure would bear little relation to the pre-existing jog positions. The fact that these can be correlated suggests the jog climb meclianism proposed. The final configuration therefore appears to conform with that of figure $17.9(\mathrm{~b})$ of Hirtl and Lothe [46].

In figure 3 it is not possible to identify in the pre-irradiation micrograpls a sufficicnt number of jogs to fully explain the post-irradiation dislocation configuration. It is possible either that a number of small pre-existing jogs were not resolved before irradiation, although their effects 
can be seen, or that new jogs are nucleating adjacent to zig-zagged sections. No evidence for jog nucleation is seen on widely dissociated dislocations with large edge character. However the nosition is less certain for narrowly dissociated near-screw dislocations. More light may be shed on this question by similar irradiations performed in an Fe-15\%Ni-17\% Cr-1\%Si alloy, which show screw disl. ocations assuming a similar, but more angular and less regular, configuration. Results from this, and other materials, will be presented at a later date.

The observations in figure 4 of dislocation motion away from a discrete line of clusters at the initial dislocation position may be linked to climb of a single jog. As in figure 1, a line of cluster damage is assumed to have formed close to the dislocation core in the early stages of the irracliation; this cluster dlamage, in nucleating preferentially within, and thus relaxing, the strain field of the dislocation, will exert a pinning force to resisi dislocation motion. Simultaneously the jog is climbing to the right and distorting neighbouring line sections. These sections will exert a line

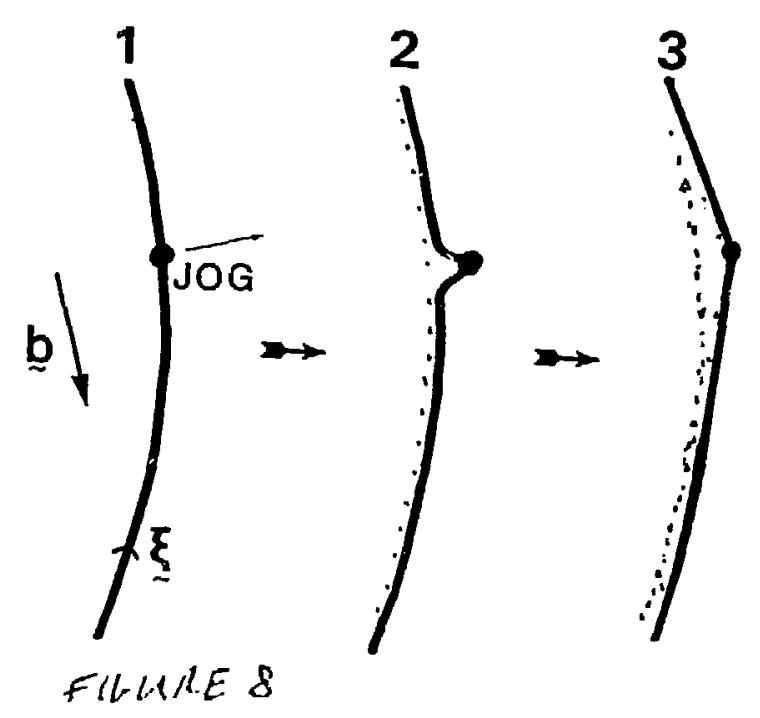
tension force acting to straighten the line. At some critical stress the lir. tension force will overcome the pinning force and the dislocation will straightien between the jog and any pinning noint, leaving a discrete line of clusters at the initial dislocation position. It is possible that another line of clusters is now nucleating close to the new dislocation position.

The above mechanism is sketched schematically in figure 8.

We have seen point defect clusters nucleate during irradiations of all dislocations of appreciable edge character, but not of dislocations of screw or near-screw character. This is consistent with the small hydrostatic strain field of near screw dislocations. The frequent observations of SFT interspersed with unidentified 3D cluster damage (such as in figure 5) would suggest that all these clusters are vacancy in nature. Small clusters, very similar to these, have previously been seen to grow to become identifiable as SFT during an in-situ irradiation experiment in silver [37]. Several tilting experiments have also confirmed both the unidentifiable clusters, and 
SFT to lie within the compressional strain field of the dislocation (c.g. figures $4(b)$ and (c)).

Given the high density of vacancy clusters close to dislocations the fate of the more mobile interstitials generated during irradiation must be considered. A greater number of interstitials than vacancies are expected to migrate to dislocations. However, the above micrographs provide no cridence for climb of the line itself and, although this possibility cannot be excluded because of the (111) foils used, it would seem unlikely that dislocations would climb so uniformly for no sign to be visible at any specimen tilt. Furthermore there is no evidence for the nucleation of interstitial loops along dislocations. A full explanacion of our observations may involve the core diffusion of irracliation generated interstitials: In figure 1, for example, tlıe dislocation is initially jog-free, possibly leading to casy core diffusion to the surfacc. Pre-existing jogs will act as favourable sites for interstilial absurption and it is supposed that the sense of jog climb observed in figures 2,3 and 4 is interstitial.

In gencral we have found climb to occur at other favourable sites as well as jogs, including sessile dislocations, Frank loops and dislocation nodes. One case where the nature of this climb can definitely be established is shown in figure 6 in which a perfect sessile dislocaiion $\overrightarrow{A D}$ has becn formed by the interaction of a dislocation $\overrightarrow{\mathrm{AT}}(\delta)$ with a series of dislocations $\overrightarrow{\mathrm{BD}}$, which are gliding along $\alpha$. This probably occurred during defiormation of the foil prior to thinning. Two of the dislocations: $\overrightarrow{\mathrm{BD}}(\alpha)$ were in the process of interacting with the dislocation $\overrightarrow{\mathrm{AD}} / \overrightarrow{\mathrm{AB}}(\delta)$, probably via a zipping mechanism, which will be discussed at a later date, when the stress was relieved. These dislocations can be seen intersecting the line in several refections of the full contrast series. Disloration $\overrightarrow{A D}$ will thercfore lie cxactly along the trace of plane $\alpha$ along which dislocations $\overrightarrow{B D}(\alpha)$ are gliding and can only move by climb.

With the scuse of the line direction as inclicated by the schematic diagram at centre, the extra half plane, perpendicular to the $90^{\circ}$ dislocation $\overrightarrow{\mathrm{AD}}$, is down and to the right. This half-plane may be similar to the edge of a Frank loop, containing a large number of jogs, or sites for point defect absorption. After irracliation the dislocation is cusped to the left of the trace along which it was formed, as confirmed by tilting to bring planes $\alpha$ vertical. This is consistent with interstitial climb either on $\alpha$ or $\delta$, probably via diffusion of interstitials from the bulk. The sharp points between the cusps lie closer to the original dislocation position are the points between which the line lias climbed. The disappearance of the jog at centre of figure $6(\mathrm{a})$ is also in a sense consistent witlı interstitial precipitation. A further corollary is provided by the observation that vacancies continue 
to cluster parallel to both glissile and sessile dislocations. These clusters lie to the right of dislocation $\overrightarrow{A D}$ in the figure and are thus within its compressional strain ficld.

The final point concerns the narrowing of partial separations under irradiation. This may be a result of radiation induced segregation [48], already observed to alter partial separations in binary' alloys [19] and which, in the Fe-Ni-Cr system, may lead to a build-up of the slower diffusing nickel $[30]$ at a sink [51], such as a stacking fault. In studies of the partial separation of equilibrium dissociated disincations by a varieiy of methods, Bampton et al [38] have highlighted a strong SFE dependence on nickel content, and an increase in nickel concentration at the stacking fault would be expected to reduce the partial separation. $\Lambda \mathrm{n}$ alternative explanation is that the narrowing is due to relaxation of the dislocalion strain ficld by the inclusion of point defect precipitates (vacancies in this case): these clusters will tend to constrict the line and may, uncler some circumstances, excrt an asymmetric stress upon the total dislocation aiding dislocation glide [52]. The latter mechanism would secm to be opcrating in irradiations performed in pure silver [37] where segregation is not a factor; however both mechanisms may be involved here and in other observations of the narrowing of partial separations in alloys $[23,31]$.

\section{Summary and Conclusions}

The above results secm to paint a consistent picture of the mechanisms of interaction of IIVEM generated point defects with pre-existing line dislocations in these two materials:

Vacancies: are seen to form a line of cluster damage within the compressional strain ficld of all dislocations which have a significant edge component. These clusters continue to grow under irradiation, whilst they remain within this compressional strain field, and are frequently observed to have aggregated sufficiently to be visible as small stacking fault tetrahedra. It should be noted that under prolonged high temperature irradiation this line of small cluster damage will cease to grow, and may even slırink, after the dislocation has moved away from its original position (e.g. figure 4) unless individual clusters are stabilized either by a gas atom or by conversion into an SFT. Under reactor irradiation conditions stabilization of these small vacancy clusters by a gas atom may lead to void formation. A new line of clusters will aggregate at the new dislocation position. Stress relaxation due to vacancy clusters may also contribute towards the narrowing of partial separations. 
Interstitials: pipe difruse along glissile dislocations until they cncountar a site, such as a jog, a length of sessile dislocation or a dislocation node, at which they can easily be assimilated. 'The resulting dislocation climb is only seen when such a favourable site is present. For glissile dislocations of sufficient edge character pre-existing jogs may be annihilated, effectively climbing sections of the line between them to form a new evenly dissociated dislocation. Interstitials now no longer have favourable siles for precipitation and pipe diffuse withos: further interaction. For screw, and near screw dislocations pre-existing jogs climb apart to form a roughly two dimensional zig-zag configuration. There is some atuence, in other irradiations, for this to cease when intervening, dissociated sccitions reach $60^{\circ}$ oricntation. As yet we have no detailed explanation for this.

Where jogs exist cilher singly or with an excess of one type, large scale motion of the dislocation is possible, regulated by opposing line tension forces. At high doses this may aid the formation of further jogs by dislocation intersections, creating further favourable sites for interstitial precipitation. Pre-existing dislocation networks, introduced by cold work and in which a large number of these favourable sites are generated, will thus have a large effect on the initial response of the materint to point defect nuxes generated within. After a certain dose, possibly dependent. upon the level of cold work introduced, the radiation response of the malierial may be allered by the mutual annihilation of some of these sites. It is hoped that analysis of the full set of irradiations will lielp to clarify some of these points.

At no stage was eviclence seen cither for the nucleation of loops directly onto the partials themselves, as might be expected were the Thomson \& Balluff [10] mechanism to be operating, or for Shockley dipole formation resulting from a CuAl-like mechanism [28]. The results do appear very similar to observations of irradiated dislocations in silver [37], in that dislocations promote the formation of dense vacancy cluster damage in their vicinity. It is possible therefore that dislocations are extremely effective at separating interstitial and vacancy fluxes, conducting interstitials away from their points of generation by pipe diffusion whilst trapping vacancies.

\section{Acknowledgements}

We would like to thank Sir Peter Hirsch F.R.S., the UKAEA, SERC and Dr. II. Wiedersich for the provision of laboratory facilities and financial support in Oxford, AERE IIarwell and 
1. Cawthorne, C., Fulton, E. J., Nature Vol.216, 1907, p.575

2. Nelson, R. S., Mazey, D. J., Report AERE R 6046, United Kingdom Atonic Energy Authority, 1969

3. Nelson, R. S., Mazey, D. J., Iludson, J. A., Journal of Nuclear Materials Vol.41, $1971, p .25 \pi$

4. Johnston, W. G., Rosolowski, J. II., Turkalo, A. M., Lauritzen, T., Journal of Nuclear Matcrials Vol.54, 1974, p.2.4

5. Walters, G. P., Jourmal of Nuclear Materials, Vol.136, 1985, p.263

6. Grecuwood, G. W., Forenıan, A. J. E., Rimmer, D. E., Journal of Nuclear Materials, Vol. ?, 1959, p.305

7. Heald, P. T., Plilosophical Magazine A, Vol.31, 1975, p.551

8. Stroh, A. N., Proceedings of the Plivsical Society B, Vol.67, 1954, p.427

9. Kimura, II., Maddin, R., Kuhlmann-Wilsdorf, D., Acta Metallurgica, Vol.7, 1959, p.145

10. Thomson, R. M., Balluffi, R. WV., Journal of Applied Pliysics, Vol.33, 1962, p.803

11. Escaig, B., Acta Met.allurgica, Vol.11, 1963, p.595

12. Friedel, J., in "Dislocations" Chapter 6, Pergammon Press, Ox[ord, 1965

13. Grilhé, J.,Boisson, M., Seshan, K., Gaboriaud, R. J., Philosophical Magazine A, Vol.36, 1977, p.923

14. Muroga, T., Araki, K., Miyamoto, Y., Yoshida, N., Journal of Nuclear Materials. Vols.155-15T, 1988, p.1118

15. Rothlıut, J., Schrörler, H., Ullmaier, I1., Philosoplical Magazine A, Vol.47, 1983, p.781

16. Norris, D. I. R., Philosophical Magazine $\underline{A}$, Vol.23, 1971, p.135

17. Singh, B. N., Leffers, T., Green, W. V., Victoria, M., Journal of Nuclear Materials, Vol.125, 1984, p.287

18. Kiritani, M., Materials Science Forum, Vols.15-18, 1987, p.1023

19. Urban, K., Phvsica stat.11s solida a , Vol.4, 1971, p.761

20. Jackson, R. K., Kemm, K., Nevin, J., Spalding, D., Rarliation Effects, Vol.35, 1978, p.1

21. Muncic, J. W., Eyre, B. L., English, C. A., Philosophical Magazine A, Vol.52, 1985, p.309

22. Muncic, J. W., English, C. A., Eyre, B. L., Philosophical Mngime $\Lambda$, Vol.56, 1987, p.453

23. Jenkins, M. L., IIardy, G. J., Materials Science Forum, Vols.15-18, 1987, p.1075 
21. Cockayne, D. J. II., Ray, I. I.. F., Whelan, M. J., Philosophical Magazine $\Lambda$, Vol.20, $1969, p .1265$

25. Cockaync, D. J. II., Journal of Microscony, Vol.98, 1973, p.116

26. Carter, C. B., Philosophical Mlagazine $\Lambda$, Vol.42, 1980, p.31

27. Carter, C. B., Cherns, D., Ilirsch, P. B., Saka, II.,

Procecelings of the 9th International Congress on elcctron microscopy,

Microscopal Society of Canada, Toronto 1978, p.32t

28. Cherns, D., Ilirsch, P. B., Saka, Il., Procredings of the Royal Socicty $\Lambda$,

Vol.371, 1980, p.213

29. As reference [12], Chapler 5 .

30. Ourmaz.d, A., Cherns, D., Ilirsch, P. B.,

Proccedings of the conference on "Microscopy of Semiconducting Matcrials", Oxford, Institute of Plysics Conference Series, Vol.60, 1981, p.39

31. Cher!s, D., Feuillet, G., Philoscnhical Magazine A, Vol.51, 1985, p.611

32. IIardy. G. J., D.Phil.Thesis, University of Oxford, 1985

33. Décamps, B., Cherns, D., Condat, M., Philosophical Magazine $\Lambda$, Vol.48, 1983, p.123

34. D.Clierns, D., Proceedings of the conference "Dislocations 1984", Aussois, France, March 1984; Ed. P.Veyssičre, p.215

35. Cockayne, D. J. II., Jenkins, M. L., Ray, I. L. F., Plilosophical Mlagazine $\Lambda$, Vol.24, 1971, p. 1383

36. Tomokiyo, Y., Kaku, K., Eguchi, T., Transactions of the Japanese Institute of Metals, Vol.15, 19ד4, p.39

37. Jenkins, M. L., Ilardy, G. J., Kïirk, M.A., Materials Science Forım, Vols.15-18, 1987, p.901

38. Bampton, C. C., Jones, I. P., Loretto, M. H., Acta Metallurgica, Vol.26, 1978, p.39

39. Miodownik, A. P., Journal of Calculation of Plase Diagrams, Vol.2, 1978, p.207

40. Thompson, N., Procecdings of the Physical Society B, Vol.66, 1953, p.481

41. Ilowic, A., Whelan, M. J., P'tocecdings of the Royal Socicly $\Lambda$, Vol.267, 1962, p.206

42. Makin, M. J., Buckley, S. N., Walters, G. P., Journal of Nuclear Materials, Vol.68, 1977, p.161; see also; Oen, O. S., Report-3813, 1965, Oak Ridge National Lalıoratory. 
43. Ilirsch, P. B., Howic, A., Nicholson, R. B., Pashley, D. W., Whelan, M. J., "Election Microscony of Thin Crystals", Butterworth, London, 1965, p.205

14. Carter, C. B., Ray, I. L. F., Philosophical Magazine $\Lambda$, Vol.29, 1974, p.1231

45. King, S. L., Jenkins, M. L., Kïrk, M. A., English, C. A., Proceedings of "EMAG/MICRO 89', London, Institute of Physics Conference Series, Vol.98, 1989, p.243

46. Hirth, J. P., Lothe, J., "Theorv of Dislocations", $2^{\text {nd }}$ ed., Wiley \& Sons, New York, 1982, p. 633

47. e.g.; Thomas, G., Whelan, M. J., Philosophical Magazine, Vol.4, 1959, p.511, and references therein.

48. Marwick, A. D., Jonrnal of Phrsics E, Vol.8, i978, p.1849

49. Saka, II., Res Meclianica, Vol.11, 1984, p.211

50. Rothınan, S. J., Nowicki, L. J., Murch, G. E., Journal of Physics F, Vol.10, 1980, p.383

51. Okamoto, P. K.., Wiedersich, II., Journal of Nuclear Materials, Vol.53, 1974, p.336

52. Hirsch, P.B., private communication 


\section{FIGURE CAPTIONS}

Figure 1: $\quad 75^{\circ}$ Dislocation in $\mathrm{Fe}-15 \% \mathrm{Ni}-17 \% \mathrm{Cr}$ (at.\%)

$0.05 \mathrm{dpa}$ at $\sim 400^{\circ} \mathrm{C}$

Figure 2: $\quad 50-70^{\circ}$ Dislocation in $\mathrm{Fe}-15 \% \mathrm{Ni}-17 \% \mathrm{Cr}$ (at.\%)

0.05 dpa at $\sim 400^{\circ} \mathrm{C}$

Figure 3: Screw Dislocation in Fc-15\%Ni-17\%Cr (at.\%)

$0.05 \mathrm{dpa}$ at $\sim 400^{\circ} \mathrm{C}$

Figure 4: Near screw to $60^{\circ}$ dislocation in Fe-25\%Ni-17\%Cr (at.\%)

$0.1 \mathrm{dpa}$ at $\sim 400^{\circ} \mathrm{C}$

Figure 5: $\quad 70^{\circ}$ Dislocation in $\mathrm{Fe}-25 \% \mathrm{Ni}-17 \% \mathrm{Cr}$ (at.\%)

0.12 dpa at $\sim 400^{\circ} \mathrm{C}$

Figure 6: Glissile and sessile dislocation in $\mathrm{Fe}-25 \% \mathrm{Ni}-17 \% \mathrm{Cr}$ (nt.\%)

$0.11 \mathrm{dpa}$ at $\sim 400^{\circ} \mathrm{C}$

Figure 7: Jog climb under interstitial super-saturation.

- sec text

Figure 8: Climb of single jog under interstitial super-saturation.

- see text 